multicultural community welfare agencies, ethnic community organisations, early childhood centres, child and adolescent mental health services and other relevant services. The use of the kit by service providers and feedback from consumers on the relevance and usefulness of the information will be monitored and evaluated by the TMHC. This information will be used to inform best practice in the area of cross-cultural health information provision.

The Multicultural Family Help Kit is an important new resource that will contribute towards the mental health information needs of culturally and linguistically diverse communities in NSW.

\section{REFERENCES}

1. Andrews G, Hall W, Teesson M, Henderson S. National Survey of Mental Health and Wellbeing, Report 2: The Mental Health of Australians. Canberra: Mental Health Branch, Commonwealth Department of Health and Aged Care, 1999.
2. For a definition of mental health literacy refer to Jorm AF, Korten AE, Jacomb PA, Christensen H, Rogers B, Pollit P. Mental health literacy: A survey of the public's ability to recognise mental disorders and their beliefs about the effectiveness of treatment. Med J Aust, 1997;166:182-186.

3. Haggerty Mrazek PJ, Haggerty RJ. Reducing risks for mental disorders: Frontiers for preventive intervention research. Washington DC: National Academy Press, 1994.

4. Marshall J. and Watt P. Child behaviour problems: A literature review of its size and nature and prevention interventions. Perth: Interagency Committee on Children's Futures, 1999.

5. Australian Bureau of Statistics. Census Data, 1996. ABS Catalogue No. 2015.0.

6. Mihalopoulos C, Pirkis J. Investigation and further development of the role of general practitioners and other primary care agencies in the delivery of mental health services to NESB consumers and their families. Melbourne: Australian Transcultural Mental Health Network, 1998.

7. McDonald R, Steel Z. Immigrants and mental health: An epidemiological analysis. Sydney: Transcultural Mental Health Centre, 1997.

The various formats of the Multicultural Family Help Kit can be ordered as follows:

Copies of the eight print versions of the kit in Arabic, Chinese (both Cantonese and Mandarin), Greek, Italian, Korean, Spanish, Turkish and Vietnamese can be ordered from: the Better Health Centre, PO Box 58, Gladesville, NSW 2111; Telephone: (02) 9816 0452; Facsimile: (02) 98160492.

The 16 audio tapes are available from: the Transcultural Mental Health Centre, LMB 7118, Parramatta BC, NSW 2150; Telephone: (02) 9840 3800; Facsimile: (02) 98403755.

From April 2000 the other six language versions of the kit (Serbian, Macedonian, Hindi, Croatian, Filipino and Tongan) can be downloaded from the TMHC Web site at www.tmhc.nsw.gov.au, or from the Multicultural Health Communication Service Web site at www.mhcs.health.nsw.gov.au.

\title{
REFUGEE HEALTH IN NSW
}

\section{Mitchell Smith}

\section{Director, NSW Refugee Health Service}

Each year over 4,000 humanitarian entrants settle in NSW. They have endured persecution and violations of their rights as human beings, sometimes torture, and almost always psychological trauma. Most have had significantly limited access to medical and dental care. Some have been exposed to adverse environmental conditions while fleeing or in refugee camps. In terms of health, refugees and other migrants with refugee-like experiences are recognised as being one of the most vulnerable groups in our society.

Source countries have altered over the decades, from the post-war and 1960s European migrations, through the South East Asian phases of the late 1970s and 1980s, to the more recent intakes from Iraq, Iran, the former Yugoslavia, and the Horn of Africa. Two-thirds of humanitarian migrants to NSW settle in the Greater West of Sydney. Smaller numbers live across metropolitan Sydney, in the Hunter and Illawarra Areas, and throughout rural areas in towns as diverse as Bathurst, Coffs Harbour and Wagga Wagga.

The NSW Department of Health has recently produced a blueprint, the first of its kind in Australia, which outlines an integrated and coordinated approach to the health needs of refugees. Called Strategic Directions in Refugee Health Care in $N S W,{ }^{1}$ the document provides a framework to guide existing service provision, and to promote collaboration in responding to the diverse health service needs of refugees. 
As part its response, the Department established the NSW Refugee Health Service (RHS), the goal of which is to protect and promote the health of refugees and people from refugee-like backgrounds living in NSW. Located at Liverpool and administered by the South Western Sydney Area Health Service (SWSAHS), the formation of the RHS was based on the bringing together of several existing programs:

- the Refugee Screening Program, established in 1977, which offered health assessments for newly arrived refugees, with a particular focus on public health screening;

- a health information program for refugees, which since 1987 has provided information on the health system in NSW to new arrivals;

- a project, previously based at the University of New South Wales's Department of General Practice in Fairfield, to improve the skills of General Practitioners (GPs) on refugee health.

Collocation of these programs sought to bring about a more coordinated approach, while additional funding of $\$ 300,000$ was provided to broaden the scope and reach of the RHS. Roles of the new service include:

- consultation with, and support for, health care workers;

- training for mainstream health service providers on refugee health and related issues, in conjunction with the NSW Service for the Treatment \& Rehabilitation of Torture \& Trauma Survivors (STARTTS);

- linking agencies that work with refugees and the health system;

- providing health information to refugees;

- health assessments with a primary health care focus;

- facilitating and conducting research in refugee health;

- advocating for health policies and services to protect and improve the health of refugees.

The creation of the RHS in April 1999 was timely, with the first plane load of Kosova evacuees from Macedonia arriving in Sydney just three weeks later. Operation Safe Haven, the Australian government's response to the United Nations High Commission for Refugees' request for temporary protection for Kosovars (and later, for East Timorese) was unusual in that it was the first time that evacuees have been brought directly to Australia.

In conjunction with the Commonwealth Department of Health and Aged Care, the NSW Health Counter Disaster Unit and SWSAHS, the RHS assisted with planning and coordination of health care provision for the 4,000 Kosova evacuees, and later for several hundred evacuees from East Timor. The RHS also contributed advice and training for staff from a range of health services and other government and non-government organisations.
Liaison at the national level has continued, with the service representing NSW Health on a Commonwealth Task Group examining public health screening issues among refugees and asylum-seeker groups.

At the State level, the RHS represents the Department on a committee convened by the Department of Immigration and Multicultural Affairs (DIMA) which brings together representatives from all government departments that provide services to newly arrived refugees.

Much of the RHS's ongoing work will build on existing service provision to refugees by mainstream and multicultural health services. A range of consultations has commenced with providers at an Area Health Service level, and will extend to include various refugee communities. Planning to meet identified needs will take place in conjunction with Area Health Services, with service agreements negotiated around specific projects and activities.

Work with GPs occurs through local Divisions of General Practice and the Royal Australian College of General Practice (RACGP). Staff contribute twice yearly to the RACGP training program for all NSW Advanced Trainees in General Practice. A number of resources to support GPs who see refugee patients have been developed, some in collaboration with other States.

Certain key health issues will also be a focus. Cuts to the Commonwealth Dental Program in 1996 had a particular affect on humanitarian entrants, many of whom have extremely poor dental health. Work is progressing at local and State levels to facilitate provision of public dental services for refugees.

The high profile nature of Operation Safe Haven raised awareness in Australia about the plight of refugees, and about displaced persons more generally. Each year, thousands of people with refugee-like experiences settle in NSW. Provision of adequate and appropriate medical care for this population is a challenge for our health system, requiring innovative approaches, and collaboration within and between health services and other agencies.

\section{REFERENCE}

1. NSW Department of Health. Strategic Directions in Refugee Health Care in NSW. Sydney: NSW Department of Health, 1999. W

For further information about the NSW Refugee Health Service contact Dr Mitchell Smith by telephone on (02) 98286600 , or by email at mitchell.smith@swsahs.nsw.gov.au. 